\title{
Functional and differential proteomic analyses to identify platelet derived factors affecting ex vivo expansion of mesenchymal stromal cells
}

\author{
Sven Kinzebach ${ }^{1}$, Lisa Dietz ${ }^{2,3,4}$, Harald Klüter ${ }^{1}$, Hermann-Josef Thierse ${ }^{2,3,5^{*}+}$ and Karen Bieback ${ }^{1 * \dagger}$
}

\begin{abstract}
Background: Multilineage differentiation, immunomodulation and secretion of trophic factors render mesenchymal stromal cells (MSC) highly attractive for clinical application. Human platelet derivatives such as pooled human platelet lysate (pHPL) and thrombin-activated platelet releasate in plasma (tPRP) have been introduced as alternatives to fetal bovine serum (FBS) to achieve GMP-compliance. However, whereas both PHPL and IPRP support similar proliferation kinetics of lipoaspirate-derived MSC (LA-MSC), only pHPL significantly accelerates bone marrow-derived MSC (BM-MSC) expansion. To identify functionally bioactive factors affecting ex vivo MSC expansion, a differential proteomic approach was performed and identified candidate proteins were evaluated within a bioassay.

Results: Two dimensional difference gel electrophoresis (2D-DIGE), MALDI-TOF analyses and complementary Western blotting revealed 20 differential protein species. 14 candidate proteins occured at higher concentrations in pHPL compared to tPRP and 6 at higher concentrations in tPRP. The candidate proteins fibrinogen and apolipoprotein A1 differentially affected LA- and BM-MSC proliferation.

In a second set of experiments, reference cytokines known to foster proliferation in FBS were tested for their effects in the human supplements. Interestingly although these cytokines promoted proliferation in FBS, they failed to do so when added to the humanized system.

Conclusions: The differential proteomic approach identified novel platelet derived factors differentially acting on human MSC proliferation. Complementary testing of reference cytokines revealed a lack of stimulation in the human supplements compared to FBS. The data describe a new coherent approach to combine proteomic technologies with functional testing to develop novel, humanized, GMP-compliant conditions for MSC expansion.
\end{abstract}

Keywords: Bone marrow, Differential proteomics, Mesenchymal stromal cells, 2D-DIGE, Mass spectrometry, Platelets

\section{Background}

Mesenchymal stromal cells (MSC) offer great potential for therapeutic application since they combine a number of biological properties such as multilineage differentiation, stromal support, immunomodulation, and secretion of trophic factors [1-3]. Due to the low frequency

\footnotetext{
*Correspondence: thierse@immunoproteomics.de; karen.bieback@medma. uni-heidelberg.de

${ }^{\dagger}$ Equal contributors

${ }^{2}$ Laboratory of Immunology \& Proteomics, Department of Dermatology, University Medical Center Mannheim, Heidelberg University, Theodor-Kutzer Ufer 1, Mannheim D-68167, Germany

'Institute of Transfusion Medicine and Immunology, Medical Faculty Mannheim, Heidelberg University; German Red Cross Blood Service BadenWürttemberg, Friedrich-Ebert-Str. 107, Mannheim, Hessen D-68167, Germany Full list of author information is available at the end of the article
}

within tissues, in general ex vivo expansion is required to achieve a clinically-relevant cell dose. This has to comply with good manufacturing practice (GMP) guidelines. Fetal bovine serum (FBS) used in many protocols, however, is critically rated by the regulatory authorities due to the possible transmission of extraneous agents as well as the risk of triggering host immune responses comprising the therapeutic success [4-7]. A chemically-defined medium sufficiently mimicking serum compounds to provide growth and attachment factors, buffering and detoxifying agents, is still under development $[5,8,9]$. Currently human supplements, including platelet derivatives and human serum from autologous, allogeneic or cord blood sources, are assessed in pre- and clinical studies to replace FBS $[8,9]$. We have previously demonstrated that pooled

\section{Biomed Central}


human serum (HS), human platelet lysate (pHPL) and thrombin-activated platelet releasate in plasma (tPRP) are promising alternatives to FBS and support the main characteristics of MSC [10-13]. Interestingly, HS, tPRP and pHPL all promoted the proliferation of MSC from adipose tissue (lipoaspirate, LA-MSC) to a comparable extent [13]. However, bone marrow-derived MSC (BM-MSC) proliferation was significantly enforced solely by pHPL [11]. The different proliferative responses raised three questions: i) which bioactive proteins differ in the lysate and the releasate, ii) do these proteins exert different effects on LA- and BM-MSC, and (iii) can we extrapolate these findings to optimize chemically-defined MSC media?

Human serum and platelet granules contain various growth factors capable of promoting cell proliferation and tissue regeneration [8]. Identification and characterization of these factors was markedly achieved by bioinformatic approaches integrating proteomic data sets from plasma, serum, the entire platelet proteome and specific subproteomes with functional data [14-18]. These analyses have provided a comprehensive list of platelet and plasma proteins and as such contributed significantly to our current biomolecular understanding of these components and their function in the human body. They support a systems biology view on platelet protein function, network modules and enable evaluation of upcoming data sets $[19,20]$.

Aiming to answer our questions we analyzed pHPL and TPRP with a differential proteomic approach and related the data to an in-depth catalog of human platelet proteins [20]. Upon integrating our own data with existing datasets on platelet factors differentially released upon activation [18,20-23], resulting potential bioactive proteins were functionally assessed on LA- and BM-MSC in vitro proliferation.

In addition, to validate our system we assessed the effects of selected reference cytokines. We chose cytokines described to enhance the proliferation of MSC in the presence of FBS asking whether these exert similar or different effects when added to pHPL or tPRP supplement.

\section{Results and discussion}

\section{Bioactive factors promoting MSC expansion}

Human platelet derivates support the expansion of MSC from different tissues without changing the differentiation capacity and immunoregulatory properties when compared to FBS supplementation (Additional file 1: Figure S1) [11,13,24,25]. Confirming previous results, pHPL-supplemented medium significantly promoted BMMSC proliferation compared to tPRP- and FBS (Figure 1B, $\mathrm{p}<0.05$ ) [11]. In contrast, $\mathrm{pHPL}$ and tPRP accelerated the proliferation of LA-MSC in a similar way when compared to FBS $(\mathrm{p}<0.05)[13]$. The specifically enhanced proliferative response of BM-MSC towards pHPL was dose- dependent, with $2.5 \%$ pHPL comparable to $10 \%$ tPRP or $10 \%$ FBS. Interestingly, in tPRP dose dependency was not obvious within the range of 10-5\%. Evaluating different batches, there were no significant differences in the proliferative response (not shown). These data clearly indicate that pHPL and tPRP contain different bioactive factors which specifically affect BM-MSC proliferation.

\section{Mass spectrometric identification of differential proteins in $\mathrm{pHPL}$ and $\mathrm{TPRP}$}

To detect and identify bioactive factors in pHPL and tPRP, a differential proteomic 2D-DIGE approach was performed (Figure 1A). After labelling pHPL and tPRP with CyDyes and subsequent 2D separation, 47 differentially occurring proteins were quantified by Delta $2 \mathrm{D}$ imaging software (Figure 2A). Selected differential proteins of pHPL and tPRP were picked from the preparative gel (Additional file 2: Figure S2) and subjected to MALDITOF analysis. In total, 19 plus one differential protein species were identified (Table 1, Figure 2A, Additional file 2: Figure S2). Six proteins appeared higher in tPRP whereas 14 proteins were more abundant in pHPL. One protein out of 20, Annexin A5, was not satisfactory identified by MS (5.6\% below scoring) and initially not considered as identified, but subsequent Western blot analysis confirmed differential expression (Table 1, Figure 2B).

\section{Verification of selected differential proteins}

First, the 2D-DIGE results were verified by SDS-PAGE and Western blot analysis in $\varnothing$ Alb/IgG-samples. Fibrinogen, apoA1, CLIC and also of Annexin A5 were differentially concentrated in $\varnothing$ Alb/IgG pHPL and tPRP samples (Figure $2 \mathrm{~B}$ ). Second, all proteins were analyzed in the eight different pHPL and tPRP batches (non- $\varnothing$ $\mathrm{Alb} / \mathrm{IgG}$ ) used as $10 \%$ supplement. CLIC1 was not detectable in the $10 \%$ supplemented medium and thus not further analysed. Fibrinogen and apoA1 were non-uniformly concentrated (Figure 3D). To define the concentration of fibrinogen and apoA1, one batch was compared to a dilution series of known concentrations of fibrinogen and apoA1 in SDS-PAGE and Western blotting. By comparing band intensities a concentration of approximately $500 \mu \mathrm{g} / \mathrm{ml}$ fibrinogen in $10 \% \mathrm{pHPL}$ and approximately $80 \mu \mathrm{g} / \mathrm{ml}$ apoA 1 in $10 \%$ tPRP-supplemented medium was rated (not shown).

\section{Influence of selected identified proteins on MSC proliferation}

Since none of the identified proteins was yet known as a mitogen for MSC, those described to affect the proliferation of other cell types were further analyzed [26-28]. To assess their bioactivity, BM- and LA-MSC were cultured in 5\% pHPL, tPRP and FBS, respectively, plus an increasing concentration of the selected candidate proteins. To 
A

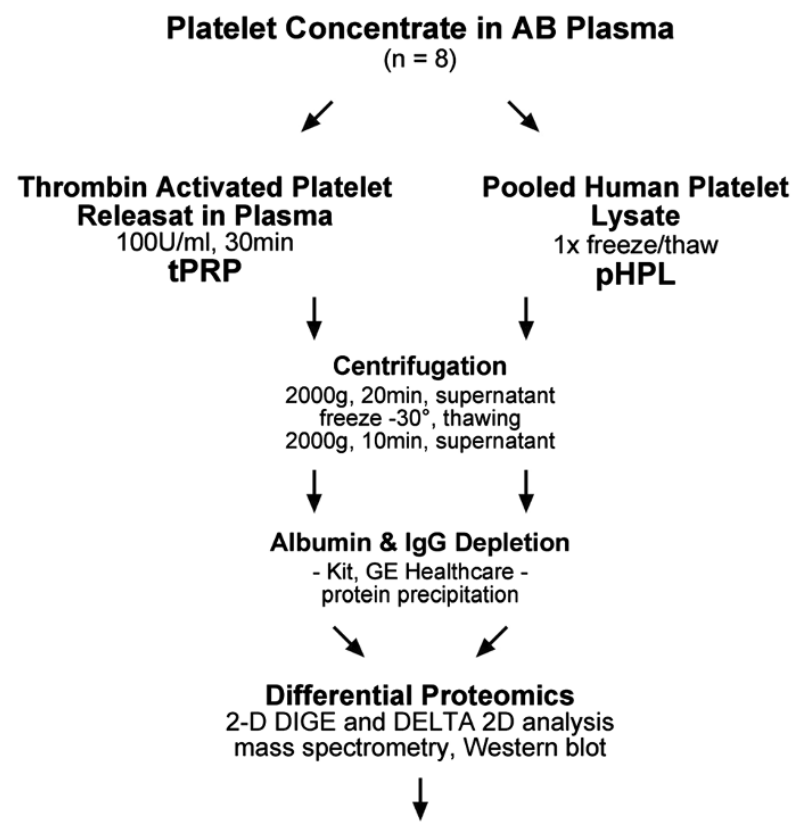

Functional Testing

of Bioactive Candidate Proteins

B

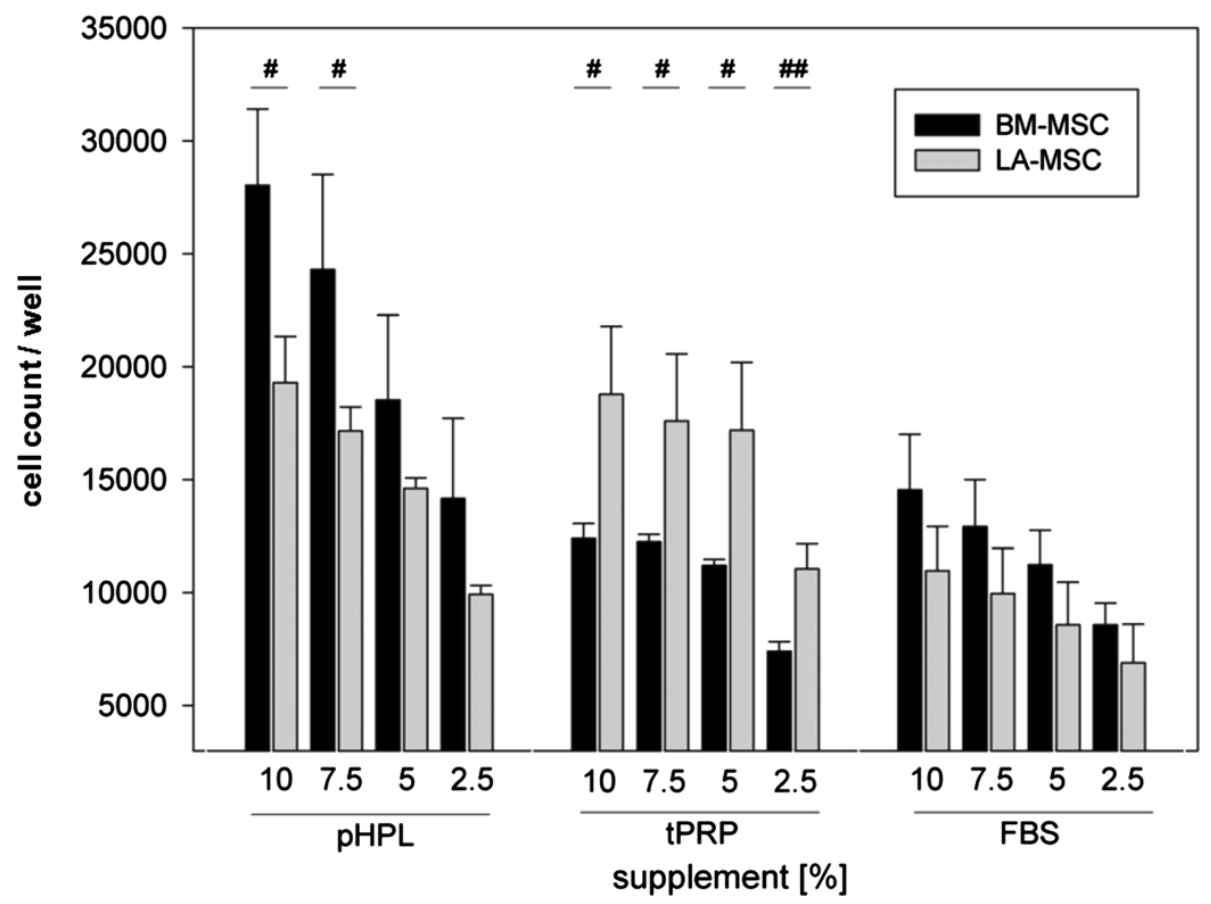

Figure 1 Experimental strategy and effect of human supplements on MSC proliferation. (A) Experimental strategy and (B) proliferation of MSC affected by the use of different supplements. Cell numbers were determined by the CellTiter-Glo assay on day 3 after seeding 3000 cells/well. Absolute MSC cell counts are shown related to decreasing supplement concentrations of pHPL, tPRP or FBS. Three independent experiments with three replicates were performed (\#: $p<0.05 ; \# \#: p<0.01$ ). 


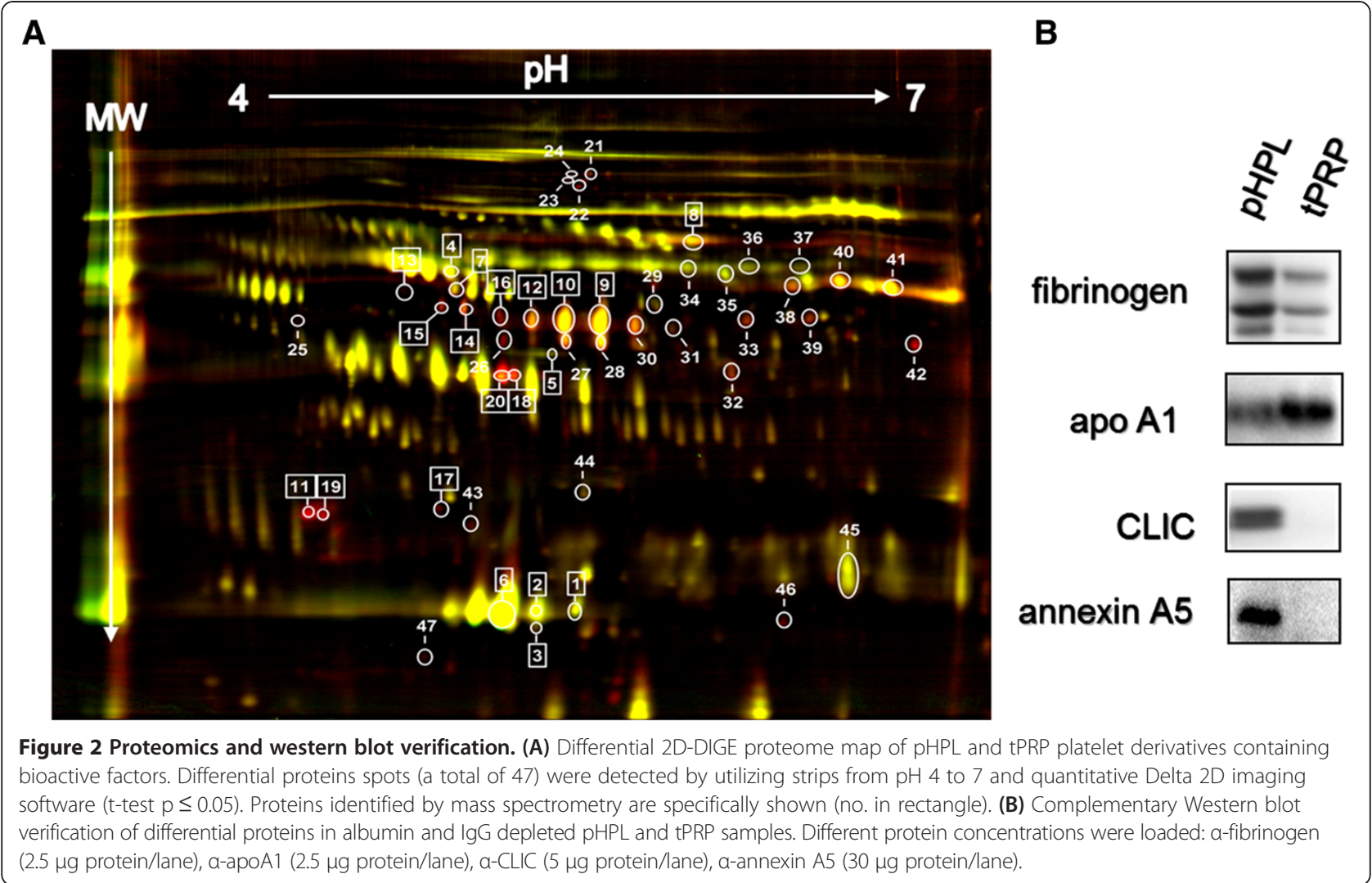

reduce variability, pHPL and tPRP batch 7 was chosen for all these experiments. Of note, none of the single candidate proteins was able to affect proliferation in completely supplement-free conditions (not shown).

\section{Fibrinogen}

$125 \mu \mathrm{g} / \mathrm{ml}$ Fibrinogen significantly stimulated LA-MSC proliferation in all three supplements compared to the unstimulated control (Figure 3A). BM-MSC exhibited strong donor variation ranging from stimulation to inhibition especially in pHPL. Fibrinogen can form a matrix to support cell adhesion, migration, but also proliferation $[26,29]$. It has already been shown to dose-dependently control BM-MSC proliferation, to reduce it at high concentrations depending on the FBS concentration [30,31]. By differential DIGE/MS, we found a differential pattern of fibrinogen species, thus spliced, truncated and posttranslational modified proteins [32,33]. Single batch Western blotting analysis failed to confirm DIGE/MS differential fibrinogen expression. Probably the primary anti-fibrinogen antibody may not be selective for all the individual isoform epitopes identified by DIGE/MS proteomics. The higher concentration of fibrinogen gamma chain species in $\mathrm{pHPL}$ well fits to the thrombin-induced conversion of fibrinogen to fibrin, consequently removed as clot in tPRP. By applying platelet-specific systems biology analysis several interaction partners of fibrinogen gamma such as ICAM1
(Intercellular Adhesion Molecule 1) or integrin beta 3 (CD61), known to be involved in rapid platelet aggregation, have been identified (Figure 3E).

\section{Apolipoprotein A1}

Only in FBS MSC proliferation became significantly affected by ApoA1, which selectively promoted LA-MSC but inhibited BM-MSC proliferation (Figure 3B). These observations illustrate the differences in MSC tissue source and supplements, respectively. ApoA1, a known major component of high density lipoprotein (HDL), has been reported to promote proliferation and to inhibit apoptosis of endothelial and vascular smooth muscle cells and to induce cardiac differentiation of embryonic stem cells [27]. Several functional interaction partners like Apo A1 binding protein and lipopolysaccharide binding protein are depicted in Figure 3F after performing platelet-specific systems biology analysis [20].

\section{ATP}

Apart from the proteins identified by the proteomic approach, the ATP-based CellTiter-Glo assay indicated higher ATP concentrations in tPRP supplement (6/8 batches; $176.5 \pm 110.7 \mathrm{nM}$ in tPRP and $52.3 \pm 34.9 \mathrm{nM}$ in pHPL). Extracellular ATP (eATP) has been described to affect various cellular features such as proliferation, apoptosis and arrest of growth, especially in neural cells [34]. In 
Table 1 MS analysis of 20 (19) differential protein spot species in pHPL and tPRPa) b)

\begin{tabular}{|c|c|c|c|c|c|c|c|c|c|}
\hline $\begin{array}{c}\text { Ratio } \\
\text { 'pHPL'/'tPRP' }\end{array}$ & Spot & Protein name & SwissProt ID & $\begin{array}{c}\text { Sequence } \\
\text { coverage (\%) }\end{array}$ & $\begin{array}{l}\text { Peptides } \\
\text { queries } \\
\text { matched }\end{array}$ & $\begin{array}{l}\text { Percental } \\
\text { match (\%) }\end{array}$ & $\begin{array}{c}\text { MOWSE } \\
\text { score }(>56 ; \\
p<0.05)\end{array}$ & MW (Da) & pl \\
\hline 0.62 & 1 & Apolipoprotein A-I & sp|P02647|APOA1_HUMAN & 80 & 29 & 33.7 & 292 & 30759 & 5.56 \\
\hline 0.65 & 2 & Apolipoprotein A-I & sp|P02647|APOA1_HUMAN & 64 & 23 & 26.4 & 205 & 30759 & 5.56 \\
\hline 0.69 & 3 & Retinol-binding protein 4 & sp|P02753|RET4_HUMAN & 67 & 11 & 15.3 & 114 & 23337 & 5.76 \\
\hline 0.71 & 4 & Angiotensinogen & sp|P01019|ANGT_HUMAN & 19 & 9 & 14.8 & 62 & 53406 & 5.87 \\
\hline 0.71 & 5 & CD5 antigen-like & sp|O43866|CD5L_HUMAN & 28 & 8 & 9 & 66 & 39603 & 5,28 \\
\hline 0.74 & 6 & Apolipoprotein A-I & sp|P02647|APOA1_HUMAN & 59 & 23 & 29.5 & 193 & 30759 & 5.56 \\
\hline 1.55 & 7 & Vitamin D-binding protein & sp|P02774|VTDB_HUMAN & 37 & 15 & 35.7 & 147 & 54526 & 5.40 \\
\hline 1.84 & 8 & Hemopexin & sp|P02790|HEMO_HUMAN & 25 & 9 & 10.1 & 68 & 52385 & 6.55 \\
\hline 2.68 & 9 & Fibrinogen gamma chain & sp|P02679|FIBG_HUMAN & 59 & 21 & 25.3 & 201 & 52106 & 5.37 \\
\hline 2.77 & 10 & Fibrinogen gamma chain & sp|P02679|FIBG_HUMAN & 56 & 21 & 23.1 & 226 & 52106 & 5.37 \\
\hline 2.98 & 11 & Tropomyosin alpha-4 chain & sp|P67936|TPM4_HUMAN & 33 & 10 & 17.2 & 83 & 28619 & 4.67 \\
\hline 3.35 & 12 & Fibrinogen gamma chain & sp|P02679|FIBG_HUMAN & 27 & 13 & 15.1 & 88 & 52106 & 5.37 \\
\hline 4.30 & 13 & Tubulin beta chain & sp|P07437|TBB5_HUMAN & 39 & 17 & 20.7 & 149 & 50095 & 4.78 \\
\hline 4.59 & 14 & Fibrinogen gamma chain & sp|P02679|FIBG_HUMAN & 56 & 21 & 24.1 & 235 & 52106 & 5.37 \\
\hline 6.00 & 15 & Fibrinogen gamma chain & sp|P02679|FIBG_HUMAN & 51 & 19 & 22.1 & 189 & 52106 & 5.37 \\
\hline 6.69 & 16 & Fibrinogen gamma chain & sp|P02679|FIBG_HUMAN & 27 & 11 & 16.7 & 73 & 52106 & 5.37 \\
\hline 10.36 & 17 & $\begin{array}{l}\text { Chloride intracellular } \\
\text { channel protein } 1\end{array}$ & sp|O00299|CLIC1_HUMAN & 43 & 9 & 18 & 88 & 27248 & 5.09 \\
\hline 10.76 & 18 & Actin, cytoplasmic 1 & sp|P60709|ACTB_HUMAN & 53 & 16 & 22.2 & 134 & 42052 & 5.29 \\
\hline 11.01 & $19^{\mathrm{b})}$ & Annexin A5 & sp|P08758|ANXA5_HUMAN & 21 & 5 & 10.4 & $53^{b)}$ & 35971 & 4.94 \\
\hline 12.27 & 20 & Actin, cytoplasmic 1 & sp|P60709|ACTB_HUMAN & 52 & 18 & 27.3 & 163 & 42052 & 5.29 \\
\hline
\end{tabular}

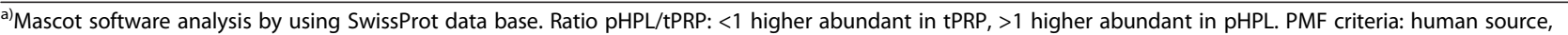
one missed tryptic cleavage, methionine oxidation, score limit $>56$. ${ }^{\text {b) }}$ Despite the fact that potential MS identification of Annexin A5 is below required scoring ( $5.6 \%$ less), this non-significant MS hit was included into the list because the suggested high ratio and protein ID was confirmed by Western blotting.

MSC, spontaneously released ATP has been associated with decreased proliferation, reversible by P2 and P2Y1 antagonists [35]. Whereas this inhibitory effect of high ATP concentrations of $10^{6} \mathrm{nM}$ was reproducible in all three supplements for BM-MSC [35,36], LA-MSC in FBS appeared refractory to growth inhibition (Figure $3 \mathrm{C}$ ). The distinct effects of eATP on different cell types have been attributed to engagement of different purinergic receptors $[37,38]$.

Besides the current experimental limitations (depletion of abundant proteins, no membrane proteins expected, whole protein-based proteomics, selected $\mathrm{pH}$ range 4-7 of IEF), we are confident that the combination of differential proteomics, database comparison and functional testing proves to be a suitable method to identify relevant factors affecting MSC proliferation. Despite the few factors tested, we were able to identify some with differential effects on MSC proliferation depending on the supplement and MSC tissue source. Thus, the major hurdle in developing a chemically-defined medium is the combination and interaction of different factors which can best be modeled by multifactorial design experiments [39].

\section{Influence of selected reference cytokines on MSC proliferation}

Cytokines were not identified within the current 2D DIGE approach probably due to their often low concentration in plasma. Therefore, within a second set of experiments selected cytokines, known to foster MSC proliferation in FBS [40-42], were added to the different supplements and MSC proliferation was measured. Here we a) tested the effect of adding different concentrations of cytokines, b) evaluated growth factor receptor expression and c) the concentration of cytokines in the culture medium/conditionened medium. We decided to use $50 \mathrm{ng} / \mathrm{ml} \mathrm{HGF,} 10 \mathrm{ng} / \mathrm{ml} \mathrm{IGF-1} \mathrm{and} 25 \mathrm{ng} / \mathrm{ml} \mathrm{bFGF}$ $[35,40,41]$. Cytokines failed to induce a proliferative response in MSC cultured with $5 \%$ platelet derivatives (Figure 4A), whereas control cells in 5\% FBS responded adequately. bFGF inhibited BM-MSC proliferation in the human supplements. Comparable findings have been observed by Cheon et al. testing the effects of EGF, FGF and ITS (insulin, transferring, selenium) on AT-MSC proliferation in FBS or human serum. In both settings, the combination of ITS and growth factors induced proliferation, whereas FGF on its own was highly effective in FBS 


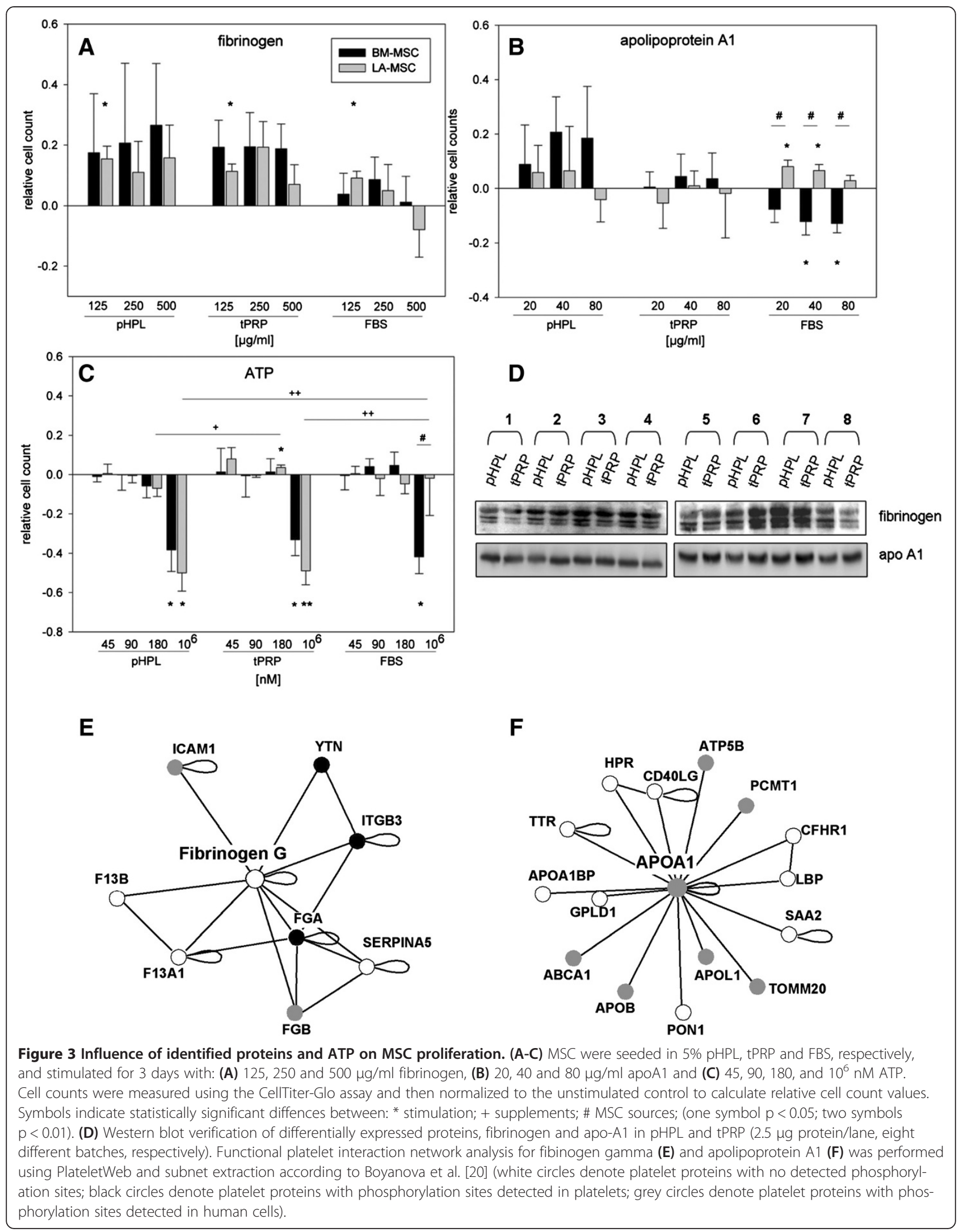



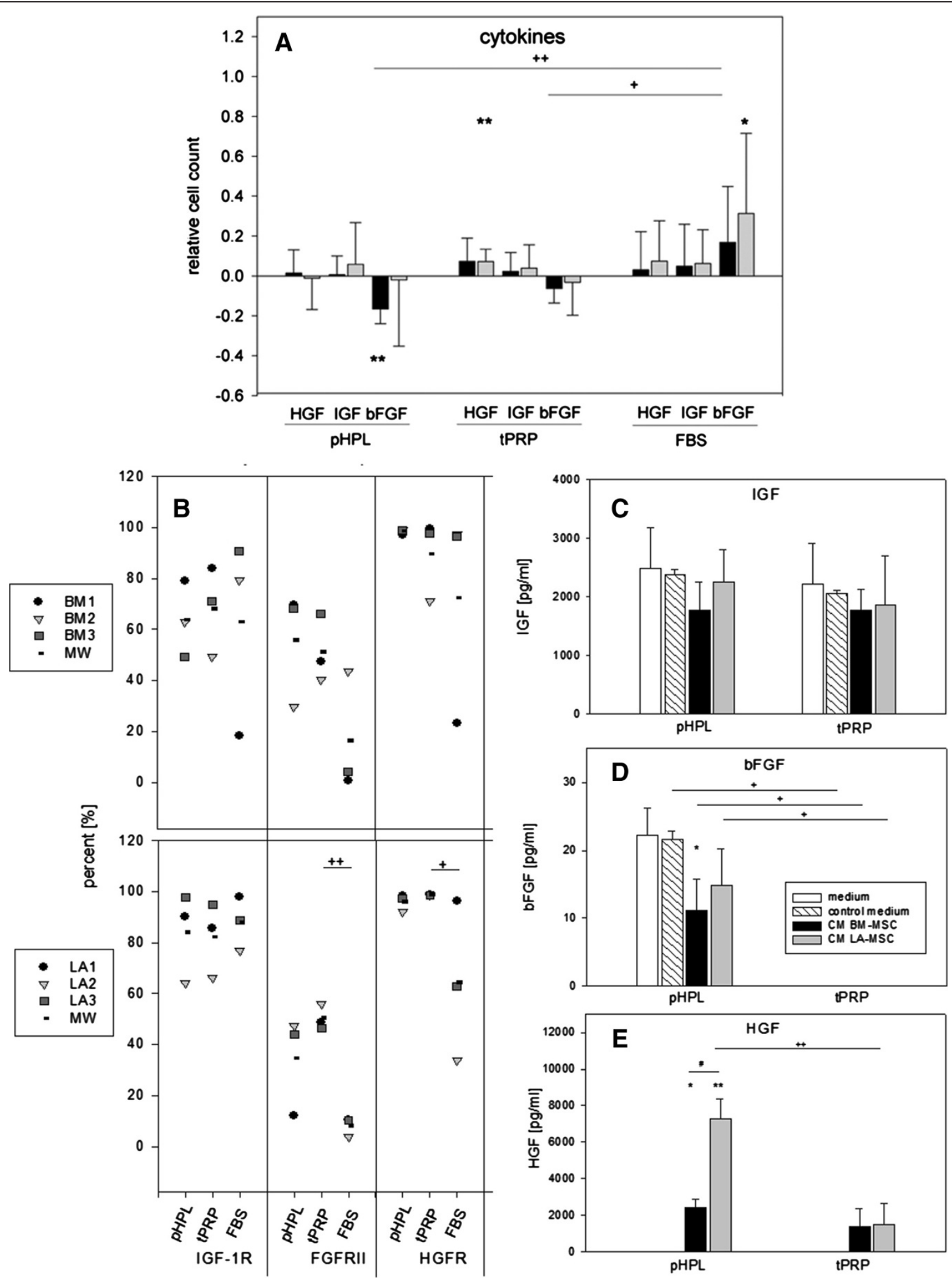

Figure 4 (See legend on next page.) 
(See figure on previous page.)

Figure 4 Influence of selected cytokines on MSC proliferation; receptor expression profiles and concentration. (A) MSC were seeded in $5 \% \mathrm{pHPL}$, tPRP and FBS, respectively, and stimulated with for 3 days with $50 \mathrm{ng} / \mathrm{ml} \mathrm{HGF,} 10 \mathrm{ng} / \mathrm{ml} \mathrm{IGF-1} \mathrm{or} 25 \mathrm{ng} / \mathrm{ml}$ bFGF. Cell counts were acquired with the CellTiter-Glo assay and then normalized to the unstimulated control to derive relative cell count values. (B)\% positivity of IGF, FGF and HGF receptor expression of BM- and LA-MSC (donors 1-3, respectively) in pHPL, tPRP and FBS assessed by flow cytometry. (C - E): IGF, FGF and HGF concentrations were determined by ELISA in PHPL and TPRP supplemented medium (medium, 6 different batches); medium stored for $24 \mathrm{~h}$ (control medium) and conditioned by MSC (CM) (each $\mathrm{n}=3$ ). Symbols indicate statistically significant diffences between: * stimulation; + supplements; \# MSC sources; (one symbol $p<0.05$; two symbols $\mathrm{p}<0.01$ ).

only [43]. Addition of EGF, bFGF and PDGFbb to 3\% platelet poor plasma, however, reached a proliferation rate comparable to FBS [44], advising a fine tuning in multifactorial design studies.

Since cytokine effects depend on their concentration as well as the receptor expression, flow cytometry analysis was performed to assess expression of growth factor receptors. FGFRII and HGFR were expressed at a significantly lower number of LA-MSC in FBS (similar, but not significant in BM-MSC) (Figure 4B). Interestingly, bFGF only induced proliferation in FBS, where both MSC types had the lowest proportion of cells expressing FGFRII (approx. 10\%). The higher proportion of FGFRII expression in the human supplements possibly rendered MSC unresponsive to additional bFGF. PDGFR- $\alpha$ expression appeared to be slightly higher in FBS, whereas PDGFR- $\beta$ and TGF- $\beta$ RII were expressed similar to FGFRII and HGFR (Additional file 3: Figure S3). With the exception of PDGFR- $\beta$ in FBS, no differences between BM- and LA-MSC were observed.

In previous studies, we addressed the cytokine content in PHPL, TPRP and conditioned media of MSC but failed to explain differential effects of pHPL and tPRP on MSC proliferation [13]. We now further analyzed the levels of selected candidates, including HGF, IGF-1, bFGF, PDGF$\mathrm{AA}, \mathrm{AB}$ and $\mathrm{BB}$ and TGF- $\beta \mathrm{II}$ in fresh medium with $10 \%$ supplement (medium), in medium incubated for $24 \mathrm{~h}$ without cells (control medium) or in medium conditioned by MSC (conditioned medium, CM). TGF- $\beta$ II was not detectable in any of the samples. IGF-1 concentrations remained largely unaffected in all conditions (Figure 4C). bFGF was detectable only in the pHPL setting, significantly diminished by BM-MSC (Figure 4D). HGF was only detectable in $\mathrm{CM}$ with apparent differences between BM- and LA-MSC in pHPL, but not in TPRP (Figure 4E). PDGF-AA levels were comparable in pHPL at all four conditions, but in tPRP values dropped in control medium to yield significant differences compared to pHPL. PDGF$\mathrm{AB}$ levels, although initially comparable between pHPL and tPRP, became strongly reduced in tPRP control medium. Similar data were obtained for PDGF-BB, with differences in pHPL CM between BM- and LA-MSC (Additional file 3: Figure S3).

Individual experimental conditions such as donor variability, but obviously also the MSC tissue origin, can largely affect the outcome as indicated in this study. Reported concentrations of cytokines in the supplements vary enormously and so do the concentrations used to stimulate MSC [45]. Numerous data indicate a strong positive effect of bFGF on MSC proliferation and osteogenic differentiation, either alone or in combination with TGF- $\beta 1[40,46]$. Platelet lysate-induced BM-MSC proliferation can be inhibited by $75 \%$ by combining neutralizing antibodies against PDGF-AB/BB, TGF- $\beta 1$ and bFGF. Stimulation with these three factors alone, however, was insufficient to promote proliferation [45]. This is in line with the data presented herein.

\section{Conclusion}

Human supplements, such as platelet derivatives, are emerging as alternatives to FBS in clinical-scale MSC manufacturing. Observed differences in the proliferative response of BM- and LA-MSC towards platelet lysate versus platelet releasate prompted us to initiate a proteomic screen of differentially expressed proteins. Although the identified differential proteins have not been previously shown to affect MSC expansion, bioactivity testing confirmed differential effects of identified proteins and selected cytokines on BM- and LA-MSC in the context of supplement (FBS vs pHPL vs tPRP).

We are confident that combining already existing data on MSC mitogens and platelet and plasma proteome databases with the current data on identified proteins and their differential bioactivity will provide a platform to identify novel factors to optimize and standardize BM- and LA-MSC culture conditions for safer clinical application.

\section{Methods}

The work involving human material has been carried out in accordance with The Code of Ethics of the World Medical Association (Declaration of Helsinki) for experiments involving humans. Use of human material has been approved by the Medical Ethical Committee II in Mannheim. Informed consent has been obtained prior to cells/tissue collection.

\section{Preparation of platelet derivates: pHPL and tPRP}

Buffy coat-derived pooled platelet concentrates (pools of four healthy blood donors, all fulfilling the criteria for 
blood donor eligibility), were prepared in AB-plasma from one donor [13]. To further minimize donor variability, each batch was prepared by pooling two platelet concentrates. To assess variability between batches, eight different pooled batches have been analyzed.

Each batch was then split into two parts. To yield the whole platelet lysate $\mathrm{pHPL}$, one part was processed by a freezing and thawing step at $-30^{\circ} \mathrm{C}$ and $37^{\circ} \mathrm{C}$. The other part was activated with $100 \mathrm{U} / \mathrm{ml}$ thrombin from human plasma (Merck) for 60 min under gentle agitation to derive the releasate tPRP, containing only the released platelet proteins in plasma. Here, in contrast to the pHPL, a fibrin clot was formed and depleted by centrifugation affecting the relative composition of platelet and plasma factors compared to pHPL. Further processing was standardized for both derivatives: samples were centrifuged at $2000 \mathrm{~g}, 20 \mathrm{~min}$ at RT, supernatant was aliquoted and cryopreserved at $-30^{\circ} \mathrm{C}$. Prior to use, derivatives were gently thawed and centrifuged at $2000 \mathrm{~g}$ for $10 \mathrm{~min}$. To prevent clotting, DMEM medium (Lonza, supplemented with $100 \mathrm{U} / \mathrm{ml}$ penicillin, $0.1 \mathrm{mg} / \mathrm{ml}$ streptomycin and $4 \mathrm{mM}$ L-glutamine (all from PAA) was added with $5 \mathrm{IU} / \mathrm{ml}$ heparin (Ratiopharm). The respective supplement was added at the indicated concentration and then the medium filtered through a $0.45 \mu \mathrm{m}$ filter. pHPL- and tPRP was always prepared fresh and used within 24 hours.

\section{Isolation and expansion of MSC}

Adipose tissue was collected from three female donors undergoing elective tumescence liposuction of the abdomen and hip/thigh region. BM aspirates were obtained from three healthy donors in the department of Internal Medicine $\mathrm{V}$ at the University Hospital of Heidelberg by puncturing the iliac crest. LA-MSC and BM-MSC were isolated by collagenase digestion or density gradient centrifugation (Ficoll-Paque Plus $=1.078 \mathrm{~g} / \mathrm{ml}$, GE Healthcare) respectively as described previously $[10,11,13,47]$. Primary cells were seeded in 10\% pHPL, tPRP and FBS (PromoCell), respectively. At a confluence of $70-80 \%$, cells were passaged using trypsin-EDTA (PAA) and either replated at a density of 200 cells per $\mathrm{cm}^{2}$ for all passages or used for experiments. MSC were characterized regarding the proliferation capacity, immune phenotype, adipo- and osteogenic differentiation potential (Additional file 1: Figure S1), according to previously described methods $[11,13]$. Chondrogenic differentiation was not performed.

\section{Differential proteomics Sample preparation}

To deplete abundant proteins, pHPL and tPRP, each pooled from two batches (a total of 16 donors and plasma from 4 donors), were pretreated with Albumin/IgG Depletion Kit
(GE Healthcare; $\varnothing \mathrm{Alb} / \mathrm{IgG}$ ) according to the manufacturer's instruction (Figure 1A). Samples were mixed with prefrozen acetone/methanol $(\mathrm{v} / \mathrm{v} 8: 1)$ for $3 \mathrm{~h}$ at $-30^{\circ} \mathrm{C}$ and subsequently centrifuged at $10000 \mathrm{~g}$ for $1 \mathrm{~h}$ at $4^{\circ} \mathrm{C}$. After washing with $500 \mu \mathrm{l}$ ice-cold acetone and centrifugation $\left(10000 \mathrm{~g}, 10 \mathrm{~min}, 4^{\circ} \mathrm{C}\right)$, the pellet was air dried and resuspended in rehydration buffer ( $6 \mathrm{M}$ urea, $2 \mathrm{M}$ thiourea, 2\% CHAPS (all Roth), 0.002\% bromophenol blue (SigmaAldrich).

\section{Two-dimensional difference gel electrophoresis}

To separate, quantify and identify differential protein signatures and protein species in $\varnothing \mathrm{Alb} / \mathrm{IgG} \mathrm{pHPL}$ and in $\varnothing \mathrm{Alb} / \mathrm{IgG}$ tPRP, multiparametric 2D-DIGE (twodimensional difference gel electrophoresis) was performed $[32,33,48,49]$. Thus, $50 \mu \mathrm{g}$ protein of each sample was labelled with CyDye DIGE Fluors (Cy3, Cy5, respectively, GE Healthcare) according to the Minimal labeling protocol (GE Healthcare). For an internal standard, equal amounts of pHPL and tPRP were mixed and $50 \mu \mathrm{g}$ from this mix labelled with Cy2. Labelled platelet derivate samples and internal standard were pooled equally to a final protein quantity of $150 \mu \mathrm{g}$. Rehydration buffer with $32 \mathrm{mM}$ DTT (Roth) and 0.5\% IPG buffer (pH 4-7, BioRad) was added to a final volume of $450 \mu \mathrm{l}$.

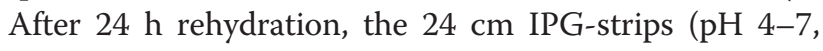
BioRad) were subjected to isoelectric focussing on an IPGphor (GE Healtcare) for a total of $58000 \mathrm{~V} / \mathrm{h}$. This specific range of $\mathrm{pH}(\mathrm{pH} 4-7)$ was chosen, since most of the proteins seem to occur in this isoelectric window, after testing IPG-strips with a range from $\mathrm{pH}$ 3-10 (data not shown). Then each strip was equilibrated in $15 \mathrm{ml}$ equilibration buffer (6 M urea, 30\% glycerol, 2\% SDS, $50 \mathrm{mM}$ Tris ( $\mathrm{pH} 8.8$ ), $0.002 \%$ bromophenol blue, all Serva), first with $32 \mathrm{mM}$ DTT for $20 \mathrm{~min}$, second with $135 \mathrm{mM}$ iodoacetamide (Roth). Equilibrated strips were transferred onto a homogenous precast $12 \%$ bis-tris polyacrylamide gel $(1 \mathrm{~mm}$, Serva) and sealed with agarose (1\% agarose, $0.002 \%$ bromophenol blue, Roth). SDSPAGE was performed with constant $17 \mathrm{~W}$ per gel and a running time until the blue front ran out of the gels (Ettan DALT II system; GE Healthcare). Three replicates were run.

\section{Advanced image warping and quantitative protein analysis}

Visualization of labelled protein spots was performed with a fluorescence scanner (FujiFilm FLA-5100). Therefore, gels were scanned with three different fluorescence filters (Cy2: Ex. 488 nm, Em. 520 nm, Filter Y520/LBB; Cy3: Ex. 532 nm, Em. 580 nm, Filter O580/DGR1; Cy5: Ex. 633 nm, Em. 670 nm, Filter R665/LPR). Sensitivity was set on $400 \mathrm{~V}$ with $50 \mu \mathrm{m} \mathrm{pixel/resolution.} \mathrm{Spot}$ detection, warping, and statistical analysis of stained or labeled samples were performed using Delta2D 3.4 
software (Decodon) as described previously [50]. For significant differential protein spot detection, sensitivity, background settings, and spot size were chosen according to the manufacturer's instruction. Images were matched using stringent warping strategy. Regulation factor was set to $1+/-0.5$ (red spots $>1.5$; green spots $<0.8$; and yellow spots $<1.5,>0.8)$.

\section{Mass spectrometry and protein identification}

Preparative gels were run $(250 \mu \mathrm{g}$ protein/gel), fixed with methanol/acetic acid $/ \mathrm{H}_{2} \mathrm{O}(40 / 10 / 50 \%)$, stained with Sybro Ruby (GE Healthcare) and scanned at $618 \mathrm{~nm}$. In addition, a sensitive coomassie G250 blue staining was performed. Matched protein spots of interest were picked manually and subjected to an in-gel tryptic digestion as described previously [51]. Briefly, after washing (100 $\mu \mathrm{l}$ $\mathrm{H}_{2} \mathrm{O}, 8 \mathrm{~min}, 37^{\circ} \mathrm{C}, 600 \mathrm{rpm}$ ), picked spots were incubated in $200 \mu \mathrm{l} 40 \mathrm{mM} \mathrm{NH}_{4} \mathrm{HCO}_{3} / \mathrm{CAN}$ (acetonitrile) (v/v 1:1) for $15 \mathrm{~min}\left(25^{\circ} \mathrm{C}, 600 \mathrm{rpm}\right)$. After incubation with $\mathrm{ACN}$ (1 min, $600 \mathrm{rpm}, \mathrm{RT}$ ), protein spots were air dried for $5 \mathrm{~min}$. For peptide mass fingerprint mapping $10 \mu \mathrm{l}$ trypsin $\left(3.5 \mu \mathrm{g} / \mu \mathrm{l}\right.$, Promega) was added for $30 \mathrm{~min}$ at $4^{\circ} \mathrm{C}$. Excessive trypsin was removed and $10 \mu \mathrm{l} 40 \mathrm{mM} \mathrm{NH}_{4} \mathrm{HCO}_{3}$ added and incubated over night at $37^{\circ} \mathrm{C}$. Samples were stored at $-30^{\circ} \mathrm{C}$.

Before MALDI analyses of digested human platelet proteins, peptides were concentrated and manually desalted using ZipTip ${ }^{\oplus}$ pipette C18 columns (Millipore). Peptides were eluted with $1 \mathrm{~mL} \alpha$-cyano-4-hydroxycinnamic acid diluted 1:7 in 1:1 ACN/0.1\% trifluoracetic acid solution and spotted on a MALDI 800-384 anchor chip target plate and analyzed automatically on a Bruker Ultraflex II using flex control, flex analysis, and Bruker BioTools software (batchmode). For external calibration, peptide calibration standard II was used (Sigma; m/z ratio from 700 to 3500) [50]. Database searches were performed using MS ion search against all entries for Homo sapiens in the Swiss-Prot database, applying the following: tryptic digest, up to one missed cleavage; fixed modifications, carbamidomethyl $(\mathrm{C})$; variable modification, and oxidation at methionine $(\mathrm{M})$. Mass tolerance was set to $7100 \mathrm{ppm}$. Identification was taken as unambiguous if the Mowse score was at least 56 (with p-value <0.05). In addition, PMF identification was verified comparing molecular weight and $\mathrm{pI}$ of the identified protein with gel position of the according protein spot.

\section{Data verification by Western Blot analysis}

Proteins were lysed in RIPA buffer (Santa Cruz Biotech). Protein concentration was measured by Bradford protein assay (Bio-Rad) and adjusted to equal concentrations. Protein lysates were mixed with loading buffer (Fermentas), separated on $12 \%$ Bis-Tris gels and then transferred onto a PVDF membrane (GE Healthcare). Primary antibodies used were: $\alpha$-Fibrinogen-Biotin pAB (IMS06-038-312, Agrisera), $\alpha$-Apolipoprotein A1 pAB (178422, Calbiochem), $\alpha$-CLIC-1 (chloride intracellular channel 1; 356.1, Santa Cruz Biotech). HRP-conjugated secondary reagents used were $\alpha$ Mouse IgG, $\alpha$-Rabbit IgG (both Dako) and Streptavidin (Calbiochem). All antibodies were dissolved in TBS, 5\% skimmed milk powder, 0.05\% Tween-20 (all Roth). Band detection was performed using enhanced chemiluminescence reagent $\left(\right.$ Amersham $^{\mathrm{TM}}$ ECL $^{\mathrm{rm}}$ Select Western Blotting Detection Reagent, GE Healthcare). Loading concentrations were assessed by Ponceau S staining and reference controls (Serva dual color protein standard III, Serva).

\section{Proliferation and stimulation assay}

To determine the proliferation rate of MSC, CellTiterGlo $^{\text {тм }}$ assay (Promega) quantifying ATP was performed. MSC in passage 2 with $70 \%$ confluence were trypsinized and seeded at a density of 3000 cells for 3 days into a black 96 well plate (Iso plate, PerkinElmer). Culture medium was either supplemented with each $10 \%, 7.5 \%, 5 \%, 2.5 \%$ pHPL, tPRP or FBS, respectively. Stimulation experiments utilized $5 \%$ of the supplements and the following substances at the indicated concentrations: fibrinogen, apolipoprotein A1 (apoA1), adenosine triphosphate (ATP) (Roche) and in a second set of experiments hepatocyte growth factor (HGF), insulin-like growth factor 1 (IGF-1) (all Calbiochem), and basic fibroblast growth factor (bFGF) (Miltenyi Biotec).

\section{Enzyme-linked immunosorbent assay (ELISA)}

In order to detect cytokines, described to induce MSC proliferation, platelet derivates ( $\mathrm{pHPL}$, tPRP $\mathrm{n}=6$; FBS $\mathrm{n}=2$ ) as well as medium of MSC (BM-, LA-MSC in FBS, pHPL, tPRP, each $n=3$ ), conditioned for $24 \mathrm{~h}$, were tested for PDGF-AA, AB, BB; IGF-1; HGF, bFGF (all Quantikine ELISA kit, R\&D Systems) by ELISA according to the manufacturer's instructions.

\section{Flow cytometry}

To assess the expression of cytokine receptors, flow cytometric analyses were performed. MSC were double-stained in $100 \mu \mathrm{l}$ cell wash (BD) with the following phycoerythrin(PE) and allophycocyanin- (APC) labelled antibodies: PDGFR- $\alpha$-PE (16A1), PDGFR- $\beta$-APC (18A2, both biolegend), TGF- $\beta$ RII-PE (FAB2411P; R\&D systems), IGFR-1APC (1H7; eBioscience), HGFR-APC (FAB35821), FGFR-PE (FAB684P; both R\&D systems). 7-Aminoactinomycin D was used for dead cell exclusion (Beckman Coulter). Stained cells were analyzed with the FACS Canto II from BD.

\section{Statistical analysis}

Statistical tests were performed using SigmaPlot 11.0 (Systat Software Inc). Data was tested for normality and equal variance before analysis. Statistical differences 
between three samples were calculated using analysis of variance (ANOVA, Holm-Sidak method; or ANOVA on ranks if equal variance testing failed, Tukey method). Comparing two samples paired or unpaired t-tests, respectively, were used. The symbols indicate: $\left(^{*}\right)$ significant difference before and after stimulation; $(+)$ significant difference between supplements; (\#) significant difference between MSC sources.

\section{Additional files}

Additional file 1: Figure S1. Phenotype, differentiation potential and immunosuppressive activity LA- and BM-MSC were cultured in 10\% FBS, PHPL and TPRP, respectively. (A) Photos were taken at identical time points post-seeding to observe cell morphology and confluence. Representative pictures of one LA-MSC and one BM-MSC batch are depicted (all 100x magnification). (B) Adipogenic and osteogenic differentiation. Cells were induced with differentiation media (adipogenic induction and maintance medium for 3 and 4 days, respectively and osteogenic induction medium, all Lonza) for 3 weeks and then stained with oil red o and van Kossa as descried previously $[11,13]$. Representative results of one LA-MSC batch are depicted (100x magnification). (C) Immunosuppressive activity was assessed by coculturing LA-MSC (ratio 1:10) with allogeneic peripheral blood leukocytes labeled with carboxyfluorescein diacetate succinimidyl ester ( $5 \mu \mathrm{M}$, Vybrant CFDA-SE cell tracker kit, Invitrogen). Leukocyte proliferation was stimulated with phytohemagglutinin ( $2.5 \mathrm{\mu g} / \mathrm{ml} \mathrm{PHA-L,} \mathrm{Roche} \mathrm{Applied} \mathrm{Science)} \mathrm{and} \mathrm{assessed} \mathrm{by} \mathrm{progressive}$ halving of CFDA-SE fluorescence (red line - control with PHA; green control without PHA). One representative experiment is depicted revealing similar dye retention and thus immunosuppressive activity of MSC in FBS, pHPL and tPRP (grey line - coculture MSC with PHA). Similar data were obtained applying BM-MSC

Additional file 2: Figure S2. Representative 2D-gel of pHPL and PRP samples. Spots marked in green occurred at higher concentrations in tPRP as compared to pHPL, whereas spots marked in red were more abundant in PHPL (pH 4-7; 24 cm strip; Sybro Ruby staining).

Additional file 3: Figure S3. Cytokines and receptor expression. (A) Flow cytometry to determine PDGFs and TGF- $\beta$ Il receptor expression (\% positivity) of BM- and LA-MSC in PHPL, tPRP and FBS. (B - D) Determination of PDGF-AA, AB, BB concentrations in six different $\mathrm{pHPL}$ and tPRP batches (10\% supplemented medium); medium stored for $24 \mathrm{~h}$ (control medium) and conditioned medium by MSC (CM) via ELISA. Symbols indicate statistically significant diffences between: * stimulation; + supplements; \# MSC sources; (one symbol $p<0.05$; two symbols $p<0.01 ; n=3$ for each condition).

\section{Authors' contributions}

SK carried out the whole experiments, including the proteomic analysis, immunoassays and functional testing, performed statistical analysis and drafted the manuscript. LD participated in the design of the study, carried out the evaluation and statistical analysis of proteomic data sets. HK participated in the design of the study and interpretation of results. HJT participated in the conception and coordination of the study, was involved in the statistical analysis and interpretation of data and drafted the manuscript. $\mathrm{KB}$ conceived of the study, participated in the design and analysis of experiments and coordinated the study. She drafted the manuscript. All authors proof read the manuscript and approved the final version.

\section{Authors' information}

SK: was a PhD student and well experienced in protein analysis, including proteomics and immunoblotting.

LD: was a PostDoc in HJTs laboratory and well experienced in proteomic analysis including mass spectometry.

HK: is head of the Institute of Transfusion Medicine and Immunology and experienced with all aspects of blood banking and transfusion services. HJT: was head of the Laboratory of Immunology \& Proteomics, Department of Dermatology and University Medical Center Mannheim, Heidelberg University, Germany; has moved to the Unit Experimental Research Immunology \& Proteomics- at the German Federal Institute for Risk Assessment.

$\mathrm{KB}$ : is head of the stem cell research department within the institute and well experienced in the field of MSC and defining human supplements to replace fetal bovine serum for GMP-compliant manufacturing processes.

\section{Acknowledgements}

We thank Dr. Patrick Wuchter for providing bone marrow aspirates, Cora Ecker, Mandy Schwalbe and Andrea Hecker for excellent technical assistance, and Daniela Griffiths and Dr. lan Haidl for critical editing the manuscript. This work was supported by research funds of the German Federal Ministry of Education and Research (START-MSC: 01GN0531 and 01GN0939) and a project commissioned by the European Community (CASCADE: FP7-223236) to KB. Funding sources were not involved in the study design or completion.

\section{Author details}

${ }^{1}$ Institute of Transfusion Medicine and Immunology, Medical Faculty Mannheim, Heidelberg University; German Red Cross Blood Service Baden-Württemberg, Friedrich-Ebert-Str. 107, Mannheim, Hessen D-68167, Germany. ${ }^{2}$ Laboratory of Immunology \& Proteomics, Department of Dermatology, University Medical Center Mannheim, Heidelberg University, Theodor-Kutzer Ufer 1, Mannheim D-68167, Germany. ${ }^{3}$ Functional Proteome Analysis, German Cancer Research Center, Heidelberg, Germany. ${ }^{4}$ Current address: Leibniz-Institut für Analytische Wissenschaften - ISAS - e.V, Otto-Hahn-Str. 6b, Dortmund 44227, Germany. ${ }^{5}$ Current address: German Federal Institute for Risk Assessment, Max-Dohrn-Str. 8-10, Berlin 10589, Germany.

Received: 14 June 2013 Accepted: 23 October 2013

Published: 30 October 2013

\section{References}

1. Pittenger MF, Mackay AM, Beck SC, Jaiswal RK, Douglas R, Mosca JD, Moorman MA, Simonetti DW, Craig S, Marshak DR: Multilineage potential of adult human mesenchymal stem cells. Science 1999, 284(5411):143-147.

2. Bieback K, Kinzebach S, Karagianni M: Translating research into clinical scale manufacturing of mesenchymal stromal cells. Stem Cells Int 2011 2010:193519.

3. Bernardo ME, Pagliara D, Locatelli F: Mesenchymal stromal cell therapy: a revolution in regenerative medicine? Bone Marrow Transplant 2012, 47(2):164-171

4. Sundin M, Ringden O, Sundberg B, Nava S, Gotherstrom C, Le Blanc K: No alloantibodies against mesenchymal stromal cells, but presence of anti-fetal calf serum antibodies, after transplantation in allogeneic hematopoietic stem cell recipients. Haematologica 2007, 92(9):1208-1215.

5. Mannello F, Tonti GA: Concise review: no breakthroughs for human mesenchymal and embryonic stem cell culture: conditioned medium, feeder layer, or feeder-free; medium with fetal calf serum, human serum, or enriched plasma; serum-free, serum replacement nonconditioned

$$
\text { or enriched plasma; serum-free, serum replacement nonconditioned }
$$

\section{Competing interests}

The authors declare that they have no competing interests. 
medium, or ad hoc formula? All that glitters is not gold! Stem Cells 2007, 25(7):1603-1609.

6. Horwitz EM, Prockop DJ, Gordon PL, Koo WW, Fitzpatrick LA, Neel MD, McCarville ME, Orchard PJ, Pyeritz RE, Brenner MK: Clinical responses to bone marrow transplantation in children with severe osteogenesis imperfecta. Blood 2001, 97(5):1227-1231.

7. EMA: Note for Guidance on Minimising the Risk of Transmitting Animal Spongiform Encephalopathy Agents Via Human and Veterinary Medicinal Products. EMA 41001 rev3 2011.

8. Kinzebach S, Bieback K: Expansion of mesenchymal stem/stromal cells under xenogenic-free culture conditions. Adv Biochem Eng Biotechnol 2013, 129:33-57

9. Tekkatte C, Gunasingh GP, Cherian KM, Sankaranarayanan K: "Humanized" stem cell culture techniques: the animal serum controversy. Stem Cells Int 2011, 2011:504723.

10. Bieback K, Ha VA, Hecker A, Grassl M, Kinzebach S, Solz H, Sticht C, Klueter $H$, Bugert P: Altered gene expression in human adipose stem cells cultured with fetal bovine serum compared to human supplements. Tissue Eng Part A 2010, 16(11):3467-3484

11. Bieback K, Hecker A, Kocaomer A, Lannert H, Schallmoser K, Strunk D, Klueter $\mathrm{H}$ : Human alternatives to fetal bovine serum for the expansion of mesenchymal stromal cells from bone marrow. Stem Cells 2009, 27(9):2331-2341.

12. Bieback K, Hecker A, Schlechter T, Hofmann I, Brousos N, Redmer T, Besser D, Klueter $\mathrm{H}$, Muller AM, Becker M: Replicative aging and differentiation potential of human adipose tissue-derived mesenchymal stromal cells expanded in pooled human or fetal bovine serum. Cytotherapy 2012, 14(5):570-583.

13. Kocaoemer A, Kern S, Klueter H, Bieback K: Human AB serum and thrombin-activated platelet-rich plasma are suitable alternatives to fetal calf serum for the expansion of mesenchymal stem cells from adipose tissue. Stem Cells 2007, 25(5):1270-1278.

14. Borzini P, Mazzucco L: Tissue regeneration and in loco administration of platelet derivatives: clinical outcome, heterogeneous products, and heterogeneity of the effector mechanisms. Transfusion 2005, 45(11):1759-1767.

15. Demidova-Rice TN, Wolf L, Deckenback J, Hamblin MR, Herman IM: Human platelet-rich plasma- and extracellular matrix-derived peptides promote impaired cutaneous wound healing in vivo. PLoS One 2012, 7(2):e32146.

16. Omenn GS, States DJ, Adamski M, Blackwell TW, Menon R, Hermjakob H, Apweiler R, Haab BB, Simpson RJ, Eddes JS, et al: Overview of the HUPO Plasma Proteome Project: results from the pilot phase with 35 collaborating laboratories and multiple analytical groups, generating a core dataset of 3020 proteins and a publicly-available database. Proteomics 2005, 5(13):3226-3245.

17. Garcia A, Prabhakar S, Brock CJ, Pearce AC, Dwek RA, Watson SP, Hebestrei $H F$, Zitzmann N: Extensive analysis of the human platelet proteome by two-dimensional gel electrophoresis and mass spectrometry. Proteomics 2004, 4(3):656-668.

18. Piersma SR, Broxterman HJ, Kapci M, de Haas RR, Hoekman K, Verheul HM, Jimenez CR: Proteomics of the TRAP-induced platelet releasate. J Proteomics 2009, 72(1):91-109.

19. Dittrich M, Birschmann I, Stuhlfelder C, Sickmann A, Herterich S, Nieswandt B, Walter U, Dandekar T: Understanding platelets. Lessons from proteomics, genomics and promises from network analysis. Thromb Haemost 2005 94(5):916-925.

20. Boyanova D, Nilla S, Birschmann I, Dandekar T, Dittrich M: PlateletWeb: a systems biologic analysis of signaling networks in human platelets. Blood 2012, 119(3):e22-e34.

21. Shai E, Rosa I, Parguina AF, Motahedeh S, Varon D, Garcia A: Comparative analysis of platelet-derived microparticles reveals differences in their amount and proteome depending on the platelet stimulus. $J$ Proteomics 2012, 76:287-296.

22. Tucker KL, Kaiser WJ, Bergeron AL, Hu H, Dong JF, Tan TH, Gibbins JM: Proteomic analysis of resting and thrombin-stimulated platelets reveals the translocation and functional relevance of HIP-55 in platelets. Proteomics 2009, 9(18):4340-4354

23. Zufferey A, Fontana P, Reny JL, Nolli S, Sanchez JC: Platelet proteomics. Mass Spectrom Rev 2012, 31(2):331-351.

24. Flemming A, Schallmoser $K$, Strunk D, Stolk M, Volk HD, Seifert M: Immunomodulative efficacy of bone marrow-derived mesenchymal stem cells cultured in human platelet lysate. J Clin Immuno/ 2011, 31(6):1143-1156.

25. Lange C, Cakiroglu F, Spiess AN, Cappallo-Obermann H, Dierlamm J, Zander AR: Accelerated and safe expansion of human mesenchymal stromal cells in animal serum-free medium for transplantation and regenerative medicine. J Cell Physiol 2007, 213(1):18-26.

26. Gardiner EE, D'Souza SE: A mitogenic action for fibrinogen mediated through intercellular adhesion molecule-1. J Biol Chem 1997, 272(24):15474-15480.

27. Ng KM, Lee YK, Lai WH, Chan YC, Fung ML, Tse HF, Siu CW: Exogenous expression of human apoA-I enhances cardiac differentiation of pluripotent stem cells. PLoS One 2011, 6(5):e19787.

28. Shi ZH, Zhao C, Wu H, Wang W, Liu XM: CLIC1 protein: a candidate prognostic biomarker for malignant-transformed hydatidiform moles. Int J Gynecol Cancer 2011, 21(1):153-160

29. Simpson-Haidaris PJ, Rybarczyk B: Tumors and fibrinogen. The role of fibrinogen as an extracellular matrix protein. Ann N Y Acad Sci 2001, 936:406-425.

30. Ode A, Duda GN, Glaeser JD, Matziolis G, Frauenschuh S, Perka C, Wilson CJ, Kasper G: Toward biomimetic materials in bone regeneration: functional behavior of mesenchymal stem cells on a broad spectrum of extracellular matrix components. J Biomed Mater Res A 2010, 95(4):1114-1124.

31. Ho W, Tawil B, Dunn JC, Wu BM: The behavior of human mesenchymal stem cells in 3D fibrin clots: dependence on fibrinogen concentration and clot structure. Tissue Eng 2006, 12(6):1587-1595.

32. Jungblut PR, Schluter H: Towards the analysis of protein species: an overview about strategies and methods. Amino Acids 2011, 41(2):219-222.

33. Schluter $H$, Apweiler $R$, Holzhutter $H G$, Jungblut PR: Finding one's way in proteomics: a protein species nomenclature. Chem Cent J 2009, 3:11.

34. Neary JT, Rathbone MP, Cattabeni F, Abbracchio MP, Burnstock G: Trophic actions of extracellular nucleotides and nucleosides on glial and neuronal cells. Trends Neurosci 1996, 19(1):13-18

35. Coppi E, Pugliese AM, Urbani S, Melani A, Cerbai E, Mazzanti B, Bosi A, Saccardi R, Pedata F: ATP modulates cell proliferation and elicits two different electrophysiological responses in human mesenchymal stem cells. Stem Cells 2007, 25(7):1840-1849.

36. Ferrari D, Gulinelli S, Salvestrini V, Lucchetti G, Zini R, Manfredini R, Caione L, Piacibello W. Ciciarello M, Rossi L, et al: Purinergic stimulation of human mesenchymal stem cells potentiates their chemotactic response to CXCL12 and increases the homing capacity and production of proinflammatory cytokines. Exp Hematol 2011, 39(3):360-374. 374 e361-365.

37. Di Virgilio F, Chiozzi P, Falzoni S, Ferrari D, Sanz JM, Venketaraman V, Baricordi OR: Cytolytic P2X purinoceptors. Cell Death Differ 1998, 5(3):191-199.

38. Ferrari D, Chiozzi P, Falzoni S, Dal Susino M, Collo G, Buell G, Di Virgilio F: ATP-mediated cytotoxicity in microglial cells. Neuropharmacology 1997 36(9):1295-1301.

39. Fan X, Liu T, Liu Y, Ma X, Cui Z: Optimization of primary culture condition for mesenchymal stem cells derived from umbilical cord blood with factorial design. Biotechnol Prog 2009, 25(2):499-507.

40. Auletta JJ, Zale EA, Welter JF, Solchaga LA: Fibroblast growth factor-2 enhances expansion of human bone marrow-derived mesenchymal stromal cells without diminishing their immunosuppressive potential. Stem Cells Int 2011, 2011:235176.

41. Neuss S, Becher E, Woltje M, Tietze L, Jahnen-Dechent W: Functional expression of HGF and HGF receptor/c-met in adult human mesenchymal stem cells suggests a role in cell mobilization, tissue repair, and wound healing. Stem Cells 2004, 22(3):405-414.

42. Scavo LM, Karas M, Murray M, Leroith D: Insulin-like growth factor-I stimulates both cell growth and lipogenesis during differentiation of human mesenchymal stem cells into adipocytes. J Clin Endocr Metab 2004, 89(7):3543-3553.

43. Cheon SJ, Kim Jl, Lee JS: Effects of growth factors and kinase inhibitors on the properties of human adipose-stromal cells in different culture conditions. Cell Biol Int 2008, 32(7):784-791.

44. Chieregato K, Castegnaro S, Madeo D, Astori G, Pegoraro M, Rodeghiero F: Epidermal growth factor, basic fibroblast growth factor and platelet-derived growth factor-bb can substitute for fetal bovine serum and compete with human platelet-rich plasma in the ex vivo expansion of mesenchymal stromal cells derived from adipose tissue. Cytotherapy 2011, 13(8):933-943.

45. Fekete N, Gadelorge M, Furst D, Maurer C, Dausend J, Fleury-Cappellesso S, Mailander V, Lotfi R, Ignatius A, Sensebe $L$, et al: Platelet lysate from whole 
blood-derived pooled platelet concentrates and apheresis-derived platelet concentrates for the isolation and expansion of human bone marrow mesenchymal stromal cells: production process, content and identification of active components. Cytotherapy 2012, 14(5):540-554.

46. Solchaga LA, Penick K, Porter JD, Goldberg VM, Caplan AI, Welter JF: FGF-2 enhances the mitotic and chondrogenic potentials of human adult bone marrow-derived mesenchymal stem cells. J Cell Physiol 2005, 203(2):398-409.

47. Kern S, Eichler H, Stoeve J, Klueter H, Bieback K: Comparative analysis of mesenchymal stem cells from bone marrow, umbilical cord blood, or adipose tissue. Stem Cells 2006, 24(5):1294-1301.

48. Shaw J, Rowlinson R, Nickson J, Stone T, Sweet A, Williams K, Tonge R: Evaluation of saturation labelling two-dimensional difference gel electrophoresis fluorescent dyes. Proteomics 2003, 3(7):1181-1195.

49. May C, Brosseron F, Chartowski P, Meyer HE, Marcus K: Differential proteome analysis using 2D-DIGE. Methods Mol Biol 2012, 893:75-82

50. Dietz L, Bosque A, Pankert P, Ohnesorge S, Merz P, Anel A, Schnolzer M, Thierse HJ: Quantitative DY-maleimide-based proteomic 2-DE-labeling strategies using human skin proteins. Proteomics 2009, 9(18):4298-4308.

51. Shevchenko A, Jensen ON, Podtelejnikov AV, Sagliocco F, Wilm M, Vorm O, Mortensen P, Boucherie H, Mann M: Linking genome and proteome by mass spectrometry: large-scale identification of yeast proteins from two dimensional gels. Proc Natl Acad Sci U S A 1996, 93(25):14440-14445.

doi:10.1186/1471-2121-14-48

Cite this article as: Kinzebach et al:: Functional and differential proteomic analyses to identify platelet derived factors affecting ex vivo expansion of mesenchymal stromal cells. BMC Cell Biology 2013 14:48.

\section{Submit your next manuscript to BioMed Central and take full advantage of:}

- Convenient online submission

- Thorough peer review

- No space constraints or color figure charges

- Immediate publication on acceptance

- Inclusion in PubMed, CAS, Scopus and Google Scholar

- Research which is freely available for redistribution 